\title{
Effects of melatonin on the proliferation and differentiation of rat adipose-derived stem cells
}

\author{
Arash Zaminy, Iraj Ragerdi Kashani, Mohammad Barbarestani, Azim Hedayatpour, \\ Reza Mahmoudi', Safoura Vardasbi², Mohammad Ali Shokrgozar ${ }^{3}$ \\ Department of Anatomy, School of Medicine, Medical Sciences, University of Tehran, ${ }^{1}$ Department of Anatomy, School \\ of Medicine, Yasouj University of Medical Sciences, ${ }^{2}$ Department of Biochemistry, School of Medicine, Medical sciences, \\ University of Tehran, ${ }^{3}$ National Cell Bank of Iran, Pasteur Institute of Iran, Tehran, Iran
}

Address for correspondence: Dr. Iraj Ragerdi Kashani, Tehran University of Medical Sciences, Faculty of Medicine, Poursina Street, Tehran, Iran. E-mail: ragerdi@sina.tums.ac.ir

\section{ABSTRACT}

Background: Osteogenesis driven by adipose-derived stem cells (ADSCs) is regulated by physiological and pathological factors. Accumulating evidence from in vitro and in vivo experiments suggests that melatonin may have an influence on bone formation. However, little is known about the effects of melatonin on osteogenesis, which thus remains to be elucidated. This study was performed to determine whether melatonin at physiological concentrations $(0.01-10 \mathrm{nM})$ could affect the in vitro proliferation and osteogenic differentiation of rat ADSCs. Materials and Methods: ADSCs were isolated from the fat of adult rats. After cell expansion in culture media and through three passages, osteogenesis was induced in a monolayer culture using osteogenic medium with or without melatonin at physiological concentrations (0.01-10 nM). After four weeks, the cultures were examined for mineralization by Alizarin Red $S$ and von Kossa staining and for alkaline phosphatase (ALP) activity using an ALP kit. Cell viability and apoptosis were also assayed by 3-(4, 5-dimethylthiazol-2-yl)-5-(3-carboxymethoxyphenyl)-2-(4-sulfophenyl)-2H-tetrazolium (MTT) assay and flow cytometry, respectively. Results: The results indicated that at physiological concentrations, melatonin suppressed proliferation and differentiation of ADSCs. These data indicate that ADSCs exposed to melatonin, had a lower ALP activity in contrast to the cells exposed to osteogenic medium alone. Similarly, mineral deposition (calcium level) also decreased in the presence of melatonin. Flow cytometry confirmed that cell growth had decreased and that the numbers of apoptotic cells had increased. Conclusion: These results suggest that the physiological concentration of melatonin has a negative effect on ADSC osteogenesis.

\section{KEY WORDS}

Adipose tissue, differentiation, melatonin, osteogenic, stem cells

\section{INTRODUCTION}

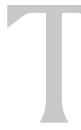

he repair of bone defects secondary to trauma, osteomyelitis, fracture nonunion and tumor resection, poses a significant problem for many clinicians, particularly, plastic, head and neck and orthopedic surgeons. ${ }^{[1]}$

Mesenchymal stem cells have recently received widespread attention because of their potential use in 
tissue engineering applications..$^{[2]}$ Mesenchymal stem cells (MSCs) are defined as self-renewable, multipotent progenitor cells with the capacity to differentiate into several distinct mesenchymal lineages. ${ }^{[3]}$

Bone marrow provides the most universal source of MSCs and the apparent pluripotent nature of bone marrow stem cells (BMSCs) makes them excellent candidates for tissue engineering. However, BMSCs have been reported to require selective lots of sera and growth factor supplements for culture expansion. ${ }^{[4]}$ Moreover, traditional bone marrow procurements, especially in volumes larger than a few milliliters may be painful, frequently requiring general or spinal anesthesia ${ }^{[4-6]}$ and may yield low numbers of MSCs upon processing. ${ }^{[7]}$ As an alternative to BMSCs, adipose tissue is particularly attractive because of its easy accessibility and abundance. ${ }^{[8-10]}$ Adipose-derived stem cells (ADSCs) obtained from lipoaspirates have been shown to have the multilineage potential to differentiate into adipogenic, chondrogenic, myogenic and osteogenic

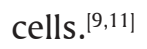

ADSCs mineralize their extracellular matrix (ECM) and show increased expression of osteocalcin and alkaline phosphatase (ALP). ${ }^{[12]}$ These factors may make ADSCs a viable clinical alternative to BMSCs.

Melatonin has been shown to play a role in many physiological systems including those involved in sleep, gastrointestinal physiology, immune defence, cardiovascular function, detoxification, reproduction and bone physiology. ${ }^{[13]}$

Melatonin influences cell proliferation and the effect of stimulation or suppression of cell division appears to depend on its concentration and the cell type examined. ${ }^{[14]}$ Melatonin's ability to directly promote osteoblast maturation was first demonstrated in preosteoblast and rat osteoblast-like osteosarcoma cells. In these cells, low concentrations of melatonin increased the mRNA levels of several genes expressed in osteoblasts including bone sialoprotein (BSP), alkaline phosphatase (ALP), osteopontin and osteocalcin. ${ }^{[15]}$ Several studies using various animal models show that melatonin prevents bone deterioration including preventing idiopathic scoliosis in adolescents ${ }^{[13,16]}$ and that it stimulates proliferation of normal cells such as human bone cells. ${ }^{[13]}$ However, there are no reports of melatonin effects on ADSC osteogenic differentiation.
In this study, we examined the effects of low and high (0.01-10 nM) physiological concentrations of melatonin on the proliferation, apoptosis and differentiation of ADSCs derived from adult rat using in vitro culture systems.

\section{MATERIALS AND METHODS}

\section{Isolation of adipose-derived stem cells}

About six to eight - weeks' old male rats were sacrified using Diethyl ether. The groin and testicular areas were shaved and prepared with standard sterile techniques. A $15 \mathrm{~mm}$ incision was made along the scrotum and the testes were pulled outward, exposing the epididymal fat pad. Epididymal adipose tissue was excised, placed on a sterile glass surface and finely minced. The tissue was then transferred to a $50 \mathrm{ml}$ conical tube and washed in Hank's Balanced Salt Solution (HBSS, Sigma). The minced tissue was placed in a sterile, $50 \mathrm{ml}$ conical tube (Greiner, Germany) containing $0.05 \%$ tissue culture grade collagenase type 1 (Sigma, St. Louis, MO.) and 5\% bovine serum albumin (BSA, Sigma). The tube was incubated at $37^{\circ} \mathrm{C}$ for $1 \mathrm{~h}$ and shaken every five minutes. Next, an equal volume of Dulbecco's Modified Eagle Medium (DMEM) with $10 \%$ fetal bovine serum (FBS) was added to neutralize the collagenase. The tube contents were filtered through a sterile $250 \mu \mathrm{m}$ nylon mesh to remove undigested debris. The digested tissue was then centrifuged at $250 \mathrm{~g}$ for five minutes and mature adipocytes were removed by aspirating the supernatant, leaving behind a pellet of cells. The cell pellet was resuspended in adipose-derived stem cell medium: DMEM/F12 (Sigma.), 10\% FBS (Gibco), $100 \mathrm{U} / \mathrm{ml}$ penicillin and $100 \mu \mathrm{g} / \mathrm{ml}$ streptomycin (Sigma). Cell counts were determined with a haemocytometer. ${ }^{[2]}$

Cell culture and expansion: The collected fat-derived stem cells were plated in $75 \mathrm{~cm}^{2}$ vented tissue culture flasks at a density of $1 \times 10^{6}$ cells per flask in DMEM with $10 \%$ FBS and $1 \%$ penicillin/streptomycin (Sigma, USA). The flasks were maintained in a tissue culture incubator at $37^{\circ} \mathrm{C}$ in an atmosphere containing $5 \%$ carbon dioxide. The media were replaced the day after the initial stem cell harvest and every third day after that. The cells were monitored for confluence on a daily basis.

The cells were subcultured when the flasks reached $80 \%$ confluence. The media were removed and cells detached by incubation with $3 \mathrm{ml}$ trypsin for 5 minutes. The cell layer was then collected into a $15 \mathrm{ml}$ conical tube and was centrifuged at $250 \mathrm{~g}$ for ten minutes. The pellet 
was resuspended with $10 \mathrm{ml}$ control media and the cells were counted. The cells were seeded into other flasks at a density of $10 \times 10^{5}$ cells per flask.

ADSCs were cultured and expanded in basal medium and used for experiments at passage 3 .

Osteogenic differentiation: After culture expansion to three passages, the cells were trypsinized and replated in T75 tissue culture flasks at a density of $10 \times 10^{5}$ cells per flask Cells were allowed to adhere and grow for three days and the media replaced with osteogenic media consisting of DMEM with 10\% fetal bovine serum (Sigma, USA), $0.1 \mu \mathrm{M}$ dexamethasone (Sigma, USA), $10 \mathrm{mM}$ betaglycerol phosphate (Sigma, USA), $50 \mu \mathrm{g} / \mathrm{ml}$ ascorbic acid2-phosphate (Sigma, USA) with or without physiological concentrations of melatonin (0.01-10 nM) (Sigma, USA). ${ }^{[2]}$

Treatment groups: Three treatment groups: osteogenic medium alone, osteogenic medium with low physiological concentration of melatonin $(0.01 \mathrm{nM})$ and osteogenic medium with a high physiological concentration of melatonin $(10 \mathrm{nM})$, were used throughout this study to analyze melatonin's effect on ADSC differentiation into osteoblasts. These studies were conducted for 28 days to determine if melatonin could modulate osteogenic differentiation of ADSCs into osteoblasts.

Confirmation of osteogenic differentiation: Confirmation of osteogenesis was done by means of von Kossa and Alizarin Red S staining (to highlight extracellular matrix calcification) and the assessment of alkaline phosphatase activity.

Von kossa staining: The cells in flasks $\left(25 \mathrm{~cm}^{2}\right)$ were rinsed with phosphate-buffered saline (PBS) (Sigma, USA) and fixed in 4\% paraformaldehyde (Sigma, USA) for $20 \mathrm{~min}$. The cells were incubated in $5 \%$ silver nitrate (Gibco, USA) in the dark and the flasks were exposed to ultraviolet light for $1 \mathrm{~h}$. The secretion of calcified extracellular matrix was observed as black nodules with von Kossa staining. ${ }^{[12]}$

Alizarin red S (ARS) staining: The cells in T25 flasks were washed with PBS and fixed in $10 \%(\mathrm{v} / \mathrm{v})$ formaldehyde (Sigma, USA) at room temperature for $20 \mathrm{~min}$. The monolayer was washed twice with excess distilled water prior to the addition of ARS $2 \%$ (Sigma, USA) ( $\mathrm{pH} 4.1$ ) per flask. The flasks were incubated at room temperature for 20 min while being shaken. After the aspiration of the unincorporated dye, the flasks were washed four times with distilled water while being shaken for 5 min. ${ }^{[17]}$

Quantification of mineralization: The analysis of the amount of calcium deposition in osteogenic medium was modified from a previous report. For the quantification of Alizarin Red S staining, $2 \mathrm{ml}$ 10\% (v/v) acetic acid was added to each well and the plate was incubated at room temperature for 30 min while being shaken. The monolayer was scraped off the plate with a cell scraper and transferred to a $15 \mathrm{ml}$ micro centrifuge tube with a wide-mouth pipette after the addition of $1 \mathrm{ml} 10 \%(\mathrm{v} / \mathrm{v})$ acetic acid to the scraped cells. After vortexing for $30 \mathrm{~s}$, the slurry was overlaid with $1.25 \mathrm{ml}$ mineral oil (Sigma, USA), heated to exactly $85^{\circ} \mathrm{C}$ for $10 \mathrm{~min}$ and transferred to ice for $5 \mathrm{~min}$. The slurry was then centrifuged at $20,000 \mathrm{~g}$ for $15 \mathrm{~min}$ and $500 \mu \mathrm{l}$ of the supernatant was removed to a new $1.5 \mathrm{ml}$ micro centrifuge tube. Two hundred microliters of $10 \%$ $(\mathrm{v} / \mathrm{v})$ ammonium hydroxide was added to neutralize the acid. In some cases, the $\mathrm{pH}$ was measured at this point to ensure that it was between 4.1 and 4.5. Absorbance of aliquots $(150 \mu \mathrm{l})$ of the supernatant was measured in triplicate at $405 \mathrm{~nm}$ in 96 well format using opaquewalled, transparent-bottomed plates. ${ }^{[17]}$

ALP activity: Cells were lysed by sonication for three cycles and centrifuged at $2000 \mathrm{~g}$ for $15 \mathrm{~min}$ at $4^{\circ} \mathrm{C}$. The supernatant was kept at $-20^{\circ} \mathrm{C}$ for the analysis of ALP activity and protein content. Protein samples were analyzed for total cellular protein concentrations and ALP activity. The total protein content of each sample was determined according to Bradford's method, using bovine serum albumin (BSA) as a standard. The ALP activity was performed using an ALP kit (Ziest Chem, Tehran, Iran) according to the manufacturer's instructions. The levels of activity were normalized with the amounts of protein in the cell lysates (units/mg protein). ${ }^{[18]}$

Cell viability assay: The MTT [3-(4, 5-dimethylthiazol2-yl)-2, 5-diphenyltetrazolium bromide] (Sigma, USA) test measures the mitochondrial (metabolic) activity in the cell culture, which reflects the number of viable cells. In brief, the cultures $\left(10 \times 10^{5}\right.$ seeded per well in a 96well plate) were washed with PBS and $200 \mu$ l MTT reagent added. Following incubation for 3 hrs in the incubator (in $5 \% \mathrm{CO}_{2}$ at $37^{\circ} \mathrm{C}$ ), the absorption of the medium was measured in an ELISA Reader (Anthon 2020) at $440 \mathrm{~nm} \cdot{ }^{[19]}$

Apoptosis detection: DNA fragmentation, as a late feature of apoptosis, was determined by flow cytometry as a 
percentage of nuclei with hypodiploid DNA content. For DNA content evaluation, the samples were fixed with $70 \%$ ethanol at $4^{\circ} \mathrm{C}$ for at least $30 \mathrm{~min}$. They were washed in PBS, resuspended in $400 \mu \mathrm{l}$ citrate buffer (Sigma, USA) and then stained with $400 \mu \mathrm{l}$ of a $50 \mu \mathrm{g} / \mathrm{ml}$ propidium iodide PI (Sigma, USA). The samples were incubated at $37^{\circ} \mathrm{C}$ for $30 \mathrm{~min}$ and then analyzed. PI red fluorescence was collected on a linear scale: the events in the hypodiploid peak identified the percentage of apoptosis. Sample acquisition was performed by FACScan flow cytometer equipped with Cell Quest software. ${ }^{[20]}$

\section{Statistical analysis}

The results are listed as the mean $\pm \mathrm{SE}$. The statistical difference was analyzed by one-way ANOVA followed by Dunnett's test. $P<0.05$ was considered to be statistically significant. All assays were performed in triplicate.

\section{RESULTS}

Isolated Rat Adipose-Derived Stem Cells: Adipose-derived stem cells grown in culture appeared spindle-shaped. Cells cultured in osteogenic media demonstrated a dramatic change in morphology from day 10 post induction, with the cells changing morphology from an elongated fibroblastic appearance to a polygonal shape [Figure 1].

Effects of melatonin on formation of mineralized bone nodules: The cytological results of ADSC cultures were convincingly positive when stained by Alizarin Red S and von Kossa after 28 days after subculture. Alizarin red S staining was used to investigate mineralized matrix formation by ADSCs. As shown in Figure 2, the intensity of staining increased in cells cultured in osteogenic medium alone when compared with cells exposed to osteogenic medium supplemented with melatonin [Figure 2].

Nodule formation by ADSCs was investigated with von Kossa staining. The first mineralized bone nodules formed by ADSCs were observed after 10 days of treatment. The addition of melatonin at physiologic concentrations to the osteogenic media decreased the formation of mineralized nodules compared with osteogenic media alone [Figure 3]. The experiments were repeated at least three times and showed similar effects.

Quantification of mineralization: Calcium level quantification was measured in three groups after 14 and 28 days following differentiation of ADSCs in osteogenic medium with or without of melatonin [Figure 4].
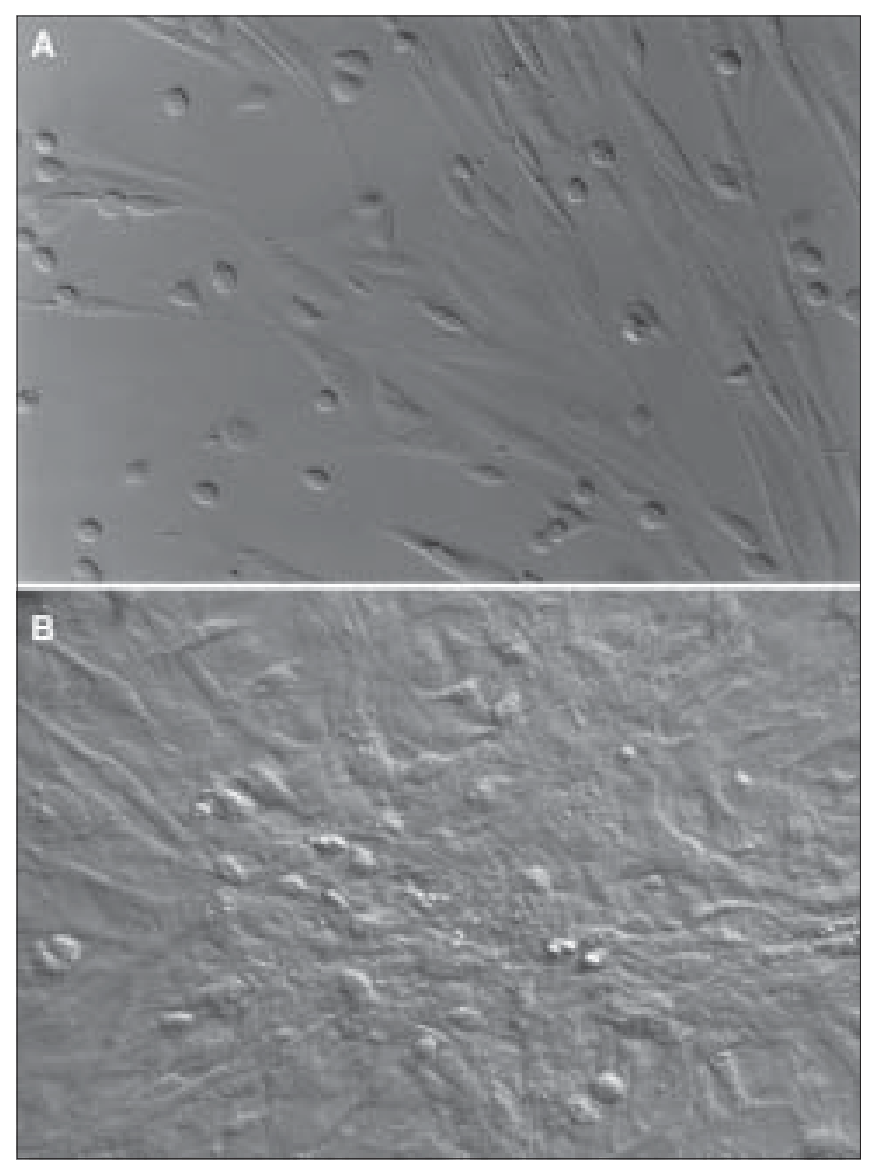

Figure 1: Initially adherent adipocyte stem cells grew as spindle-shaped cells that developed into multipolar fibroblastoid cells (A). They gradually reached confluency on the $10^{\text {th }}$ day

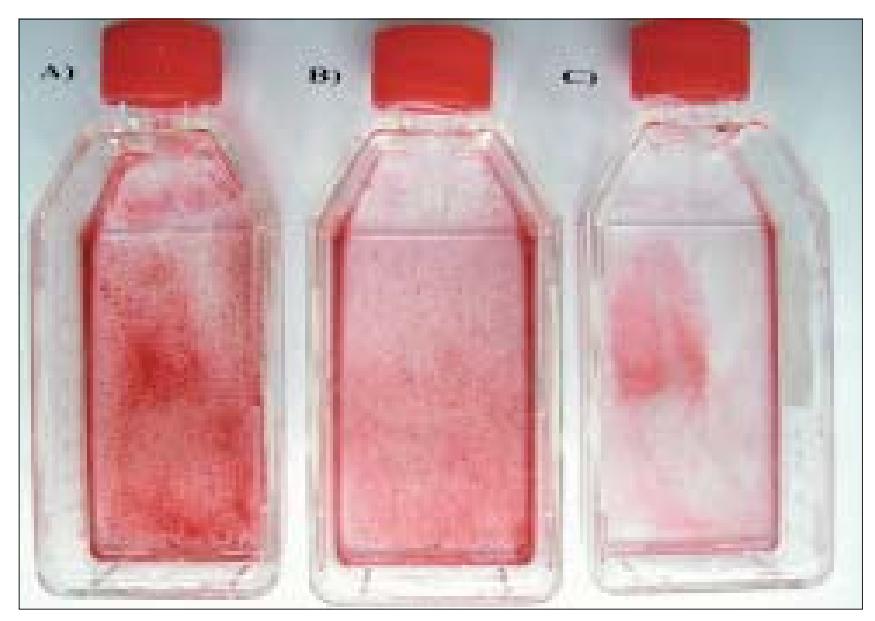

Figure 2: Alizarin Red S staining after osteogenic differentiation. Staining for mineral deposition was performed for ADSCs after 28 days. The osteogenic medium alone group was the control group. (A) Control medium (B) in presence of melatonin $10 \mathrm{nM},(\mathrm{C})$ in presence of melatonin $0.01 \mathrm{nM}$

Effects of melatonin on ALP activity: As a marker for ADSC differentiation into osteoblasts, ALP levels were measured after 14 and 28 days. As shown in Figure 5, ALP activity increased in ADSCs following incubation in osteogenic medium alone when compared with cells exposed to 


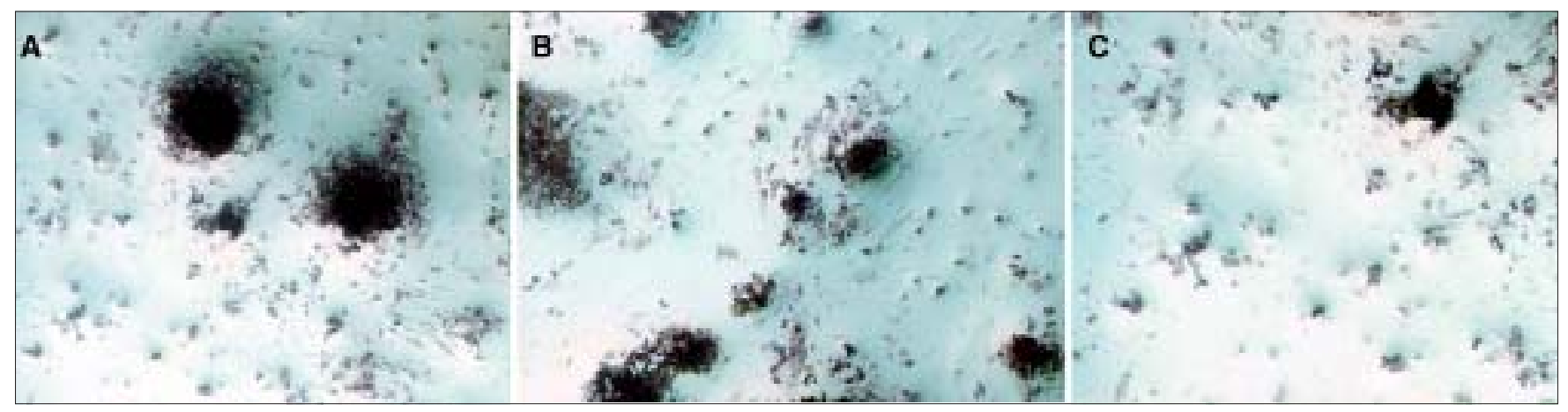

Figure 3: Von Kossa staining after osteogenic differentiation of adipocyte stem cells. This staining was done only for demonstrating osteogenic differentiation after 28 days. (A) Osteogenic medium alone, (B) Osteogenic medium in presence of melatonin10 nM, (C) Osteogenic medium in presence of melatonin $0.01 \mathrm{nM}$

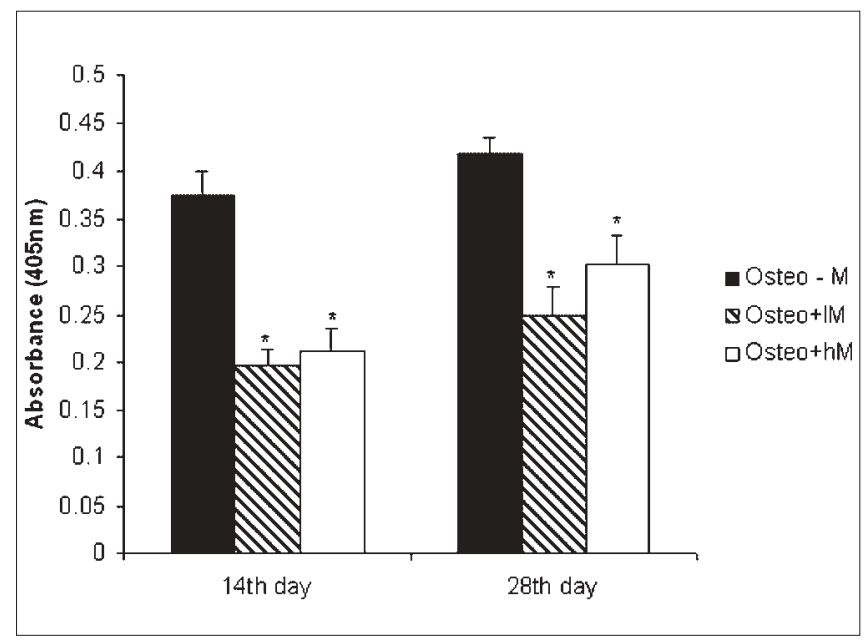

Figure 4: Calcium deposition. The ADSCs were cultured in osteogenic medium in the absence and presence of physiological concentrations of melatonin (0.01-10 $\mathrm{nM})$ for 28 days in flasks $\left(25 \mathrm{~cm}^{2}\right)$ as a monolayer culture. The osteogenic medium alone group was the control group. Calcium depositions were measured as described in Materials and Methods. Values are mean $\pm \mathrm{SE}$ $\left({ }^{\star} P<0.05\right)$. AD: Adipose-derived stem cells, Cont: control, IM: melatonin $0.01 \mathrm{nM}, \mathrm{hM}$ : melatonin $10 \mathrm{nM}$

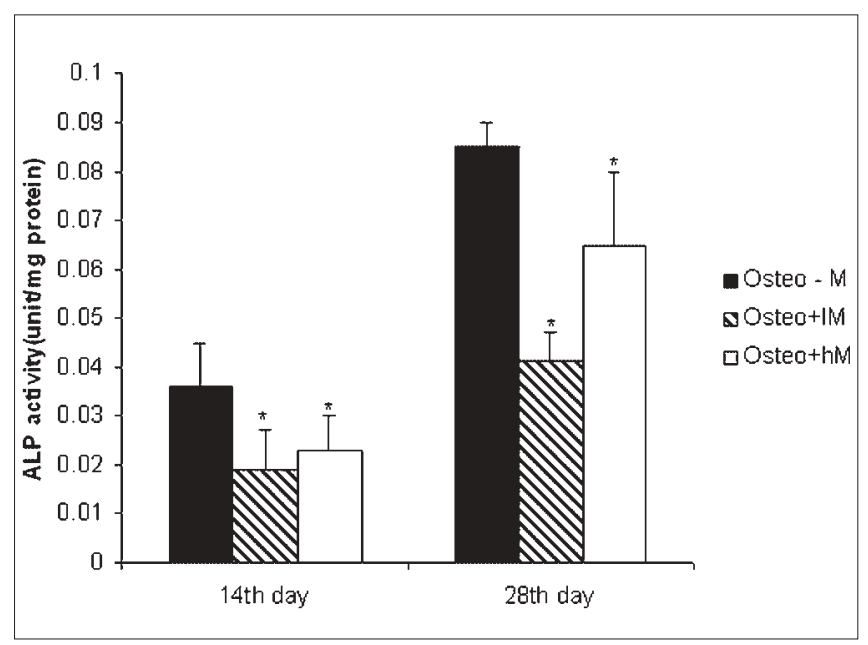

Figure 5: ALP activity in adipocyte stem cells on osteogenic differentiation on days 14 and 28 . The cells were plated at $10 \times 10^{5}$ cells/flask and cultured in osteogenic medium with or without physiologic concentration of melatonin. The osteogenic medium alone group was the control group. Values are mean $\pm \mathrm{SE}$ $\left({ }^{\star} P<0.05\right)$. ADSCs: Adipose-derived stem cells, Cont: control, IM: melatonin $0.01 \mathrm{nM}, \mathrm{hM}$ : melatonin $10 \mathrm{nM}$

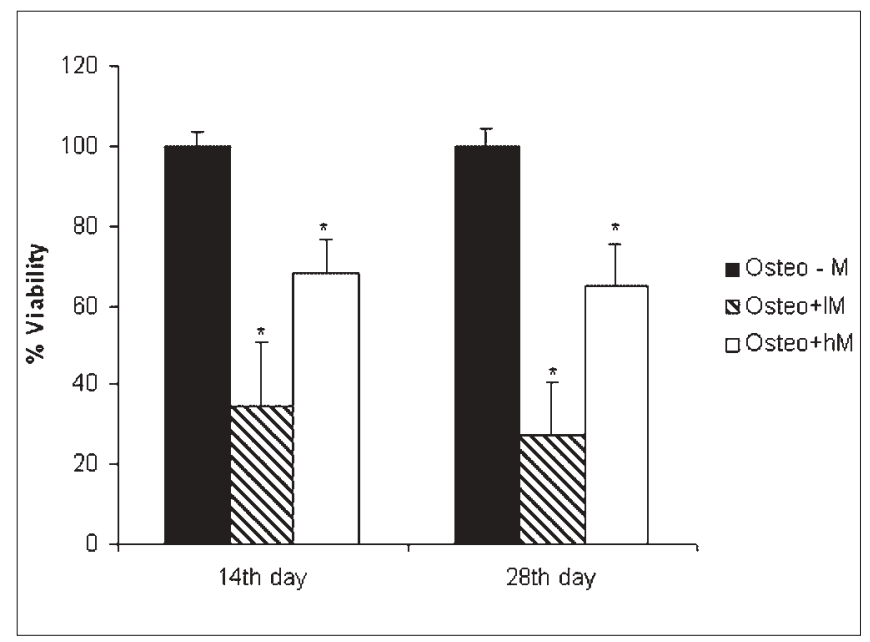

Figure 6: Effect of physiologic concentration of melatonin on the viability of adipose-derived stem cells. The cells were plated at $10 \times 10^{5}$ cells/well and cultured in osteogenic medium with or without physiologic concentration of melatonin for 28 days. Cell viability was measured by MTT assay on $14^{\text {th }}$, $28^{\text {th }}$ days. The osteogenic medium alone group was the control group. Values are mean \pm SE $(n=3)\left({ }^{\star} P<0.05\right)$. Cont: control, IM: melatonin $0.01 \mathrm{nM}, \mathrm{hM}$ : melatonin $10 \mathrm{nM}$

osteogenic medium containing melatonin [Figure 5].

Effects of melatonin on viability of ADSCS: The physiological concentrations of melatonin (0.01-10 nM) affect viability of ADSCs at 14 and 28 days after melatonin treatment as assessed by the MTT assay [Figure 6].

\section{Effects of melatonin on apoptosis of ADSCs}

To accurately quantitate the incidence of apoptotic cells in the defined ADSCs population, we used flow cytometry to detect content of DNA in cells labeled by propidium iodide. As shown in Figure 7, the incidence of apoptotic ADSC cells is increased following incubation in osteogenic medium supplemented with melatonin when compared with cells exposed to osteogenic medium alone. A decrease in cell growth was detected after 24 and $72 \mathrm{~h}$ of melatonin treatment but growth again increased with prolonged treatment. 

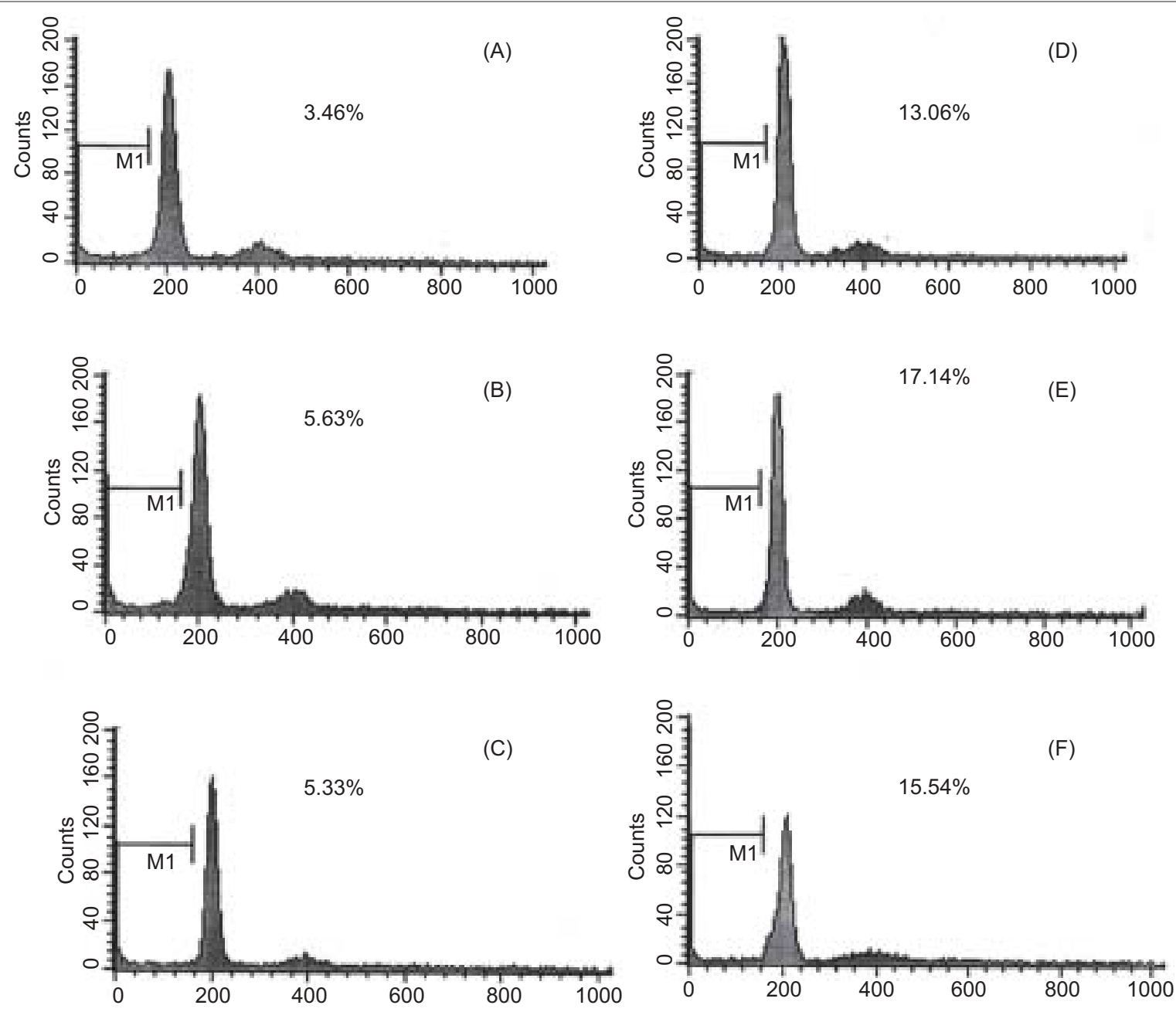

Figure 7: Flow cytometric analysis of DNA content for detection of apoptosis after 24 and $72 \mathrm{~h}$ of melatonin treatment. The cells were plated at $10 \times 10^{5}$ cells/flask and cultured in osteogenic medium in presence of melatonin. A, D after $24,72 \mathrm{~h}$ treatment with osteogenic medium alone, respectively. B, E: after $24,72 \mathrm{~h}$ treatment with osteogenic medium in presence of melatonin $0.01 \mathrm{nM}$, respectively. C, F: after $24,72 \mathrm{~h}$ treatment with osteogenic medium in presence of melatonin $10 \mathrm{nM}$, respectively

\section{DISCUSSION}

Our results clearly show that melatonin modulates the proliferative and differentiative ability of ADSCs in a concentration- and time-dependent manner.

One of the most interesting functions of physiological concentrations of melatonin in the present study was that ADSCs which had been propagated in melatonincontaining media exhibited a decrease in proliferation and osteogenic differentiation. The researchers observed when ADSCs were exposed to melatonin, ALP activity and mineral deposition decreased $(13,14)$. This decrease can be due to the reduction in the number of cells, which was demonstrated by the results of both the MTT assay and flow cytometry. In the present study, it was demonstrated that in melatonin-containing media, the progression of the apoptotic type of ADSCs is not prevented; rather, it was exaggerated by melatonin. The induction of apoptosis by melatonin in the absence of other drugs is not a common effect of this indole in normal cells. Melatonin influences cell proliferation and differentiation and the effect of stimulation or suppression of cell division appears to depend on its concentration and the cell type examined. ${ }^{[14]}$ Antiproliferative effects of melatonin have been demonstrated in vivo and in vitro in a number of cancer cells ${ }^{[21,22]}$ and normal cells. ${ }^{[23,24]}$ In contrast, pharmacological concentrations of melatonin $(10-100 \mathrm{mM})$ stimulate the proliferation of normal cells such as human bone cells. ${ }^{[17,25]}$ The fact that melatonin may affect cell growth in a biphasic manner was first reported by Slominski and Pruski in experiments with cultured rat melanoma cells. ${ }^{[26]}$ In that study, low concentrations of melatonin suppressed human melanoma cell growth, while higher concentrations stimulated such growth. These findings led Roth et al. to explore the effect of melatonin on cell growth in rat 
pheochromacytoma cells (PC12 cells)..$^{[27]}$

Similar to the above findings with human melanoma cells, melatonin induced a biphasic dose response for cell growth in the PC12 cell model. More specifically, at low concentrations, melatonin suppressed PC12 cell growth, while at a higher concentrations, it prevented cell death. ${ }^{|27|}$ Thus, melatonin differentially suppressed proliferation in different cell lines. Melatonin's behavior was complex, affecting the cell cycle presumably by different mechanisms according to its dose. The intensity of the different responses to melatonin could be related to the cell - line-specific pattern of melatonin cellular receptors and cytosolic protein expression. ${ }^{[26]}$

In summary, it is premature to offer firm conclusions about such findings except to indicate that biphasic apoptotic responses reliably occur. However, the fact that these observations are quite recent suggests that they will stimulate more exploration in this important lowdose research area.

\section{REFERENCES}

1. Huang JI, Beanes SR, Zhu M, Lorenz HP, Hedrick MH, Benhaim P. Rat extramedullary adipose tissue as a source of osteochondrogenic progenitor cells. Plast Reconstr Surg 2002;109:1033-41.

2. Hattori H, Masuoka K, Sato M, Ishihara M, Asazuma T, Takase B, et al. Bone formation using human adipose tissue-derived stromal cells and a biodegradable scaffold. J Biomed Mater Res 2006;76:230-9.

3. Caplan AL. Review: Mesenchymal stem cells: Cell-based reconstructive therapy in orthopedics. Tissue Eng 2005;11: 1198-211.

4. Auquier P, Macquart-Moulin G, Moatti JP, Blache JL, Novakovitch G, Blaise D, et al. Comparison of anxiety, pain and discomfort in two procedures of hematopoietic stem cell collection: Leukacytapheresis and bone marrow harvest. Bone Marrow Transplant 1995;16:541-7.

5. AuquierP,Macquart-MoulinG, MoattiJP,BlacheJL, Novakovitch G, Blaise $\mathrm{D}$, et al. Comparison of anxiety and pain in two procedures of hematopoietic stem cell collection: Cytapheresis and bone marrow collection. Bull Cancer 1995;82:582-8.

6. Pittenger MF, Mackay AM, Beck SC, Jaiswal RK, Douglas R, Mosca JD, et al. Multilineage potential of adult human mesenchymal stem cells. Science 1999;284:143-7.

7. Nishimori M, Yamada Y, Hoshi K, Akiyama Y, Hoshi Y, Morishima Y, et al. Health related quality of life of unrelated bone marrow donors in Japan. Blood 2002;99:1995-2001.

8. Zuk PA, Zhu M, Ashjian P, De Ugarte DA, Huang JI, Mizuno H, et al. Human adipose tissue is a source of multipotent stem cells. Moll Biol Cell 2002;13:4279-95.

9. Zuk PA, Zhu M, Mizuno H, Huang J, Futrell JW, Katz AJ, et al. Multilineage cells from human adipose tissue: Implications for cell-based therapies. Tissue Eng 2001;7:211-28.
10. Nathan S, Das De S, Thambyah A, Fen C, Goh J, Lee EH. Cellbased therapy in the repair of osteochondral defects: A novel use for adipose tissue. Tissue Eng 2003;9:733-44.

11. Jaiswal N, Haynesworth SE, Caplan AI, Bruder SP. Osteogenic differentiation of purified, culture-expanded human mesenchymal stem cells in vitro. J Cell Biochem 1997;64:295-312.

12. Halvorsen YD, Franklin D, Bond AL, Hitt DC, Auchter C, Boskey AL, et al. Extracellular matrix mineralization and osteoblast gene expression by human adipose tissue-derived stromal cells. Tissue Eng 2001;7:729-41.

13. Satomura K, Tobiume S, Tokuyama R, Yamasaki Y, Kudoh K, Maeda $\mathrm{E}$, et al. Melatonin at pharmacological doses enhances human osteoblastic differentiation in vitro and promotes mouse cortical bone formation in vivo. J Pineal Res 2007;42:231-9.

14. Sainz RM, Mayo JC, Rodriguez C, Tan DX, Lopez-Burillo S, Reiter RJ.Melatonin and cell death: Differential actions on apoptosis in normal and cancer cells. Cell Mol Life Sci 2003;60:1407-26.

15. Roth JA, Kim BG, Lin WL, Cho MI. Melatonin promotes osteoblast differentiation and bone formation. J Biol Chem 1999;274:22041-7.

16. Moreau A, Wang DS, Forget S, Azeddine B, Angeloni D, Fraschini $\mathrm{F}$, et al. Melatonin signaling dysfunction in adolescent idiopathic scoliosis. Spine 2004;29:1772-81.

17. Gregory CA, Gunn WG, Peister A, Prockop DJ. An Alizarin red-based assay of mineralization by adherent cells in culture: Comparison with cetylpyridinium chloride extraction. Anal Biochem 2004;329:77-84.

18. Bradford MM. A rapid and sensitive method for the quantitation of microgram quantities of protein utilizing the principle of proteindye binding. Anal Biochem 1976;72:248-54. 19. Merklein F, Hendrich C, Nöth U, Kochinki G, Rader CP, Schütze N, et al. Standardized tests of bone implant surfaces with an osteoblast cell culture system [Orthopedic standard materials]. Biomed Tech (Berl) 1998;43:354-9.

20. Luchetti F, Canonico B, Mannello F, Masoni C, D'Emilio A, Battistelli $\mathrm{M}$, et al. Melatonin prevents apoptosis induced by UV-B treatment in U937 cell line. J Pineal Res 2006;40:158-67.

21. Chucharoen $P$, Chetsawang B, PutthaprasartC, Srikiatkhachorn A, Govitrapong P. The presence of melatonin receptors and inhibitory effect of melatonin on hydrogen peroxide-induced endothelial nitric oxide synthase expression in bovine cerebral blood vessels. J Pineal Res 2007;43:35-41.

22. Karasek M. Melatonin, human aging and age-related diseases. Exp Gerontol 2004;39:1723-9.

23. Zwirska-Korczala K, Jochem J, Adamczyk-Sowa M, Sowa P, Polaniak R, Birkner $\mathrm{E}$, et al. Influence of melatonin on cell proliferation, antioxidative enzyme activities and lipid peroxidation in 3T3-L1 preadipocytes: An in vitro study. J Physiol Pharmacol 2005;56:S91-9.

24. Moriya T, Horie N, Mitome M, Shinohara K. Melatonin influences the proliferative and differentiative activity of neural stem cells. J Pineal Res 2007;42:411-8.

25. Roth JA, Rosenblatt T, Lis A, Bucelli R. Melatonin-indced suppression of PC12 cell growth is mediated by its $\mathrm{Gi}$ coupled transmembrane receptors. Brain Res 2001;16:919:139-46.

26. Slominisky A, Pruski D. Melatonin inhibit proliferation and melanogenesis in rodent melanoma cells. Exp Cell Res 1993;206:189-94.

27. Roth JA, Rabin R, Agnello K. Melatonin suppression of PC12 cell growth and death. Brain Res 1997;768:63-70.

Source of Support: Nil, Conflict of Interest: None declared. 